\title{
INGEKOMEN BOEKEN
}

Prof. Dr.S. Kleerekoper, Vergelijkend leerboek der Bedrijfseconomie dl. II Uitg. P. Noordhoff, Groningen. Prijs $f$ 25.-.

Enige economische en sociale aspecten van de automatisering voor bedrijf en maatschappij. Rapport $2 \mathrm{e}$ Commissie automatisering van het Nederlands Instituut voor Efficiency.

C. A. van den Heuvel \& C. H. Bosboom, Bedrijfseconomische grondslagen. Uitg. P. Noordhoff N.V., Groningen. Prijs f 5,75.

Dr. A. M. Groot, Voorraadbeheersing, assortimentsbepaling en conditiepolitiek. Uitg. Samsom N.V., Alphen a/d Rijn. Prijs f 13,75.

J. W. van Belkum en Th. J. van der Meer, Toepassing van elektronica in de administratie. Ulitg. Samsom N.V., Alphen a/d Rijn. Prijs f 7,90.

Jaarverslag 1958 Landbouweconomisch Instituut.

Drs. S. C. Bakkenist en It. H. C. King, De interne stedelijke bestuursorganisatie van de gemeente Amsterdam. Litg. Stadsdrukkerij van Amsterdam. Prijs $f 19,50$.

Prof. Dr. B. Schendstok, Fiscale winstbeginselen in Nederland. Uitg. N.V. Uitgeversmaatschappij AE. E. Kluwer, Deventer. Prijs f 8,15.

Centraal Bureau voor de Statistiek. Belastingdruk op gezinnen, statistische en econometrische onderzoekingen 2e kwartaal 1959. Uitgever: Uitgeversmaatschappij W. de Haan N.V., Zeist.

Economisch Instituut voor de Bouwnijverheid - Bouw Research.

Dr. L. Lancée, Fiscale winstsplitsing. Uitg. Uitgeversmaatschappij $A$. E. Kluwer, Deventer. Prijs f 9,75.

A. G. ter Hennepe, Praktische bedrijfseconomie. Uitg. G. W. van det Wiel $\mathcal{E}$ Co., Arnhem. Prijs f 7,90.

Centraal Bureau voor de Statistiek. Bedrijfsvergelijkende meting van de productiviteit in de grafische industrie-Boekdrukkerijen. Uitg. Uitgeversmaatschappij W. de Haan N.V., Zeist. Prijs f 20, - .

Idem - Boekbinderijen. Prijs f 20, - .

Landbouw Economische Instituut, De kosten van opbrengsten in de landbouw per bedrijf en per product.

Dr. A. Mas, Inleiding tot de accountancy (algemeen deel). Centrum voor bedrijfseconomisch onderzoek van het Instituut voor Toegepaste Economische wetenschappen der Leuvense Universiteit, Leuven. Prijs Bfrs 320, - . J. F. Mulder en J. M. van Oorschot, Grondslagen van de administratieve automatisering. Uitg. Vuga-Boekerij/G. W. van der Wiel \& Co., Arnhem. Prijs $f$ 12,75.

De hervorming van de onderneming, publikatie van de Dr. Wiarda Beckmanstichting. Uitg. N.V. de Arbeiderspers. Prijs f 6,90.

Prof. Dr. F. L. van Muiswinkel, De handelsonderneming. Uitg. N.V. Noordhollandsche Uitgeversmaatschappij. Amsterdam. Prijs $f$ 12,50.

De belastingheffing in de Euromarktlanden, vertaald en bewerkt door P. den Boer. Uitg. N.V. Uitgevers-maatschappij $A$. E. Kluwer, Deventer. Prijs $f 7,50$.

$\mathrm{m} \mathrm{a} \mathrm{b}$ blz. 452 